\title{
Coworking: an analysis of coworking strategies for interaction and innovation
}

\author{
Author(s) \\ Cabral, Victor; Van Winden, Willem \\ DOI \\ 10.1504/IJKBD.2016.080869

\section{Publication date} \\ 2016 \\ Document Version \\ Author accepted manuscript (AAM)
}

Published in

International Journal of Knowledge-Based Development

Link to publication

Citation for published version (APA):

Cabral, V., \& Van Winden, W. (2016). Coworking: an analysis of coworking strategies for interaction and innovation. International Journal of Knowledge-Based Development, 7(4), 357-377.

https://doi.org/10.1504/IJKBD.2016.080869

It is not permitted to download or to forward/distribute the text or part of it without the consent of the author(s) and/or copyright holder(s), other than for strictly personal, individual use, unless the work is under an open content license (like Creative Commons).

If you believe that digital publication of certain material infringes any of your rights or (privacy) interests,

please let the Library know, stating your reasons. In case of a legitimate complaint, the Library will make the material inaccessible and/or remove it from the website. Please contact the library:

https://www.amsterdamuas.com/library/contact/questions, or send a letter to: University Library (Library of the University of Amsterdam and Amsterdam University of Applied Sciences), Secretariat, Singel 425, 1012 WP Amsterdam, The Netherlands. You will be contacted as soon as possible. 


\section{Coworking: An analysis of coworking strategies for interaction and innovation}

Conference Paper · April 2016

DOI: $10.13140 / R G \cdot 2 \cdot 1.4404 .5208$

CITATIONS

0

2 authors:
READS

401

\section{Victor Cabral}

Amsterdam University of Applied Sciences/Cen.. 3 PUBLICATIONS 0 CITATIONS

SEE PROFILE
Willem van Winden

Amsterdam University of Applied Sciences/Cen... 55 PUBLICATIONS 465 CITATIONS

SEE PROFILE

Some of the authors of this publication are also working on these related projects: 
Regional Studies Association Annual Conference in Graz, Austria 3 ${ }^{\text {rd }}$ - 6th April, 2016

\title{
Coworking: An analysis of coworking strategies for interaction and innovation. A working paper.
}

\author{
Authors: \\ Victor Abreu Cabral, Amsterdam University of Applied Sciences \\ v.cabral@hva.nl \\ Willem van Winden, Amsterdam University of Applied Sciences \\ Center for Applied Research on Economics and Management \\ w.van.winden@hva.nl
}

March 2016 


\section{$\underline{\text { Abstract }}$}

This paper analyses how managed coworking spaces affect the innovation process of their members. Managed coworking spaces are working environments for independent professionals, with an active role of the manager of the space to foster collaboration and interaction. These locations emerged in the late 2000s and were designed to host people who endeavor to break isolation and to find a convivial environment that favors meetings and collaboration (Moriset, 2013).

It is often taken for granted that coworking contributes to innovation (Botsman \& Rogers, 2011). Earlier research discussed outcomes of coworking, such as cooperative working (e.g. Leforestier, 2009, Spinuzzi, 2012), getting access to new knowledge (van Winden et al., 2012), or having new business opportunities (Groot, 2013). Yet, it is not fully understood how coworking spaces can be effective in fostering these outcomes, and what role management could play.

The managers of coworking spaces deploy a variety of strategies to foster interaction and collaboration, but there has been very little systematic analysis of the effects on interaction and innovation. This paper proposes a typology of strategic management tools applied by coworking spaces, and aims to shed light on the effectiveness for interaction and innovation.

In the empirical part, we describe and analyze two coworking spaces in Amsterdam. The implications for proprietors of coworking spaces and policy makers are analyzed in view of the potential contributions of these spaces to local collaborations, knowledge transfer and new business opportunities.

Keywords: Coworking spaces, interaction strategies, innovation, knowledge exchange, entrepreneurial outcomes 


\section{Introduction}

Firms and knowledge workers in industrialized economies increasingly experiment with innovative work practices and new work locations (Appelbaum, 2013). Mobile technology enables professionals to work in other places than conventional offices (Brown \& Green, 2001). Locations such as in libraries, lodges, hotels, or coffee houses have become increasingly popular as places to work. Part of the attractiveness of such places is that they offer an intermediate space between home and work (a.k.a. a "Third Place", Oldenburg, 1989) away from distractions and with a social and inspiring atmosphere. A drawback of most of these places is that they do not provide interactive and collaborative environments which for achieving innovations is important (Amin and Roberts, 2008). Coworking spaces, on other hand, do offer this environment.

Coworking is a growing phenomenon and is widely recognized. The term was coined by Brad Neuberg, an engineer who founded the Spiral Muse in San Francisco in 2005. Coworking spaces can be defined as "open-plan office environments where workers work next to other unaffiliated professionals for a fee" (Spinuzzi, 2012). The concept is getting anchored in the work landscape of major business cities, with a concentration in locations often referred to as "creative cities", such as San Francisco, New York, London, Berlin, and Amsterdam (Moriset, 2013). Such cities as Amsterdam are rich in innovative cultural and creative industries (Kloosterman, 2008) which increasingly show 'nomad' working practices (Gandini, 2015) and use alternative working spaces, including as coworking spaces. The idea of coworking is built around the idea of community-building, collaboration, openness and accessibility (Coworking Wiki, n.d.). Implicitly, it is often assumed that coworking contributes to innovation (Botsman \& Rogers, 2011). What underlies the assumption is that in collaborative environments, social relations are main factors of productivity leading to new product opportunities. Coworking spaces are also regarded as "serendipity accelerators" (Moriset, 2013) and workers are said to seek places to maximize serendipity and potential interaction with peers. Moreover, they access coworking spaces with the purpose of fostering networking practices ("It's all about who you know") and highly value the collaborative environment to feed their innovation and creativity (Leforestier, 2009).

To support social capital, collaboration, and community-building, managers of coworking spaces increasingly deploy synergy management strategies to foster interaction (van Winden et al., 2013), assuming that innovation and knowledge exchange are social practices (Amin and Roberts, 2008). Yet, it is not fully understood which conditions are most favorable to support interaction and 
innovation. Therefore, this paper aims to explore the effects of strategic management tools on interaction between members in coworking spaces and the entrepreneurial outcomes of coworking.

We ask ourselves the following three questions: 1) Which strategic management tools are used in coworking spaces to make workers interact?, 2) To what extent do these tools facilitate interaction between workers?, and 3) How do these tools enable innovation? To date, little empirical research has been done regarding this topic. By studying coworking practices at the micro level, this paper contributes to our understanding of coworking as an emergent activity and sheds light on the question how strategic management tools impact the process of interaction and innovation. This paper will first review relevant literature on workplace interaction, innovation, and strategies for interaction. We then introduce 4 strategic management tools for interaction. Next, we explore these tools in two managed coworking spaces. 18 coworkers were interviewed at the two coworking sites and the results will be discussed. We end with conclusions, policy implications and questions for further research.

\section{Literature}

What do we know about the role of space for interaction? How do coworking spaces contribute to innovation? Which strategies can be applied to foster interaction? This section contains a literature review that serves as a basis for an analytical framework in which we propose 4 strategic management tools for interaction and innovation.

\subsection{Coworking spaces: Spaces to interact}

Goffman (1955) defines interaction as a process by which we act and react to those around us. It is basically, a social exchange between two or more individuals. Coworking spaces are spaces where workers from different professional and cognitive backgrounds can interact. Hillman (2008) found that workers who frequently go to coworking spaces want to bring the social dimension back into their working life, want to join a community (Leforestier, 2009) or depend on networks for new business opportunities. Meeting new people is a reason for professionals to go to coworking spaces, with the aim to access additional knowledge or skills (Senoo et al., 2007; Nonaka and Takeuchi, 1995). Meeting new people can also be of importance in many economic decisions and working outcomes, bridging resources, acquiring information, learning how to do one's work or solving problems (e.g. Ellison et al., 2013; Hutchins, 1991; Lave \& Wenger, 1991).

Coworking spaces support interaction by offering shared open spaces (physical or virtual) and a focus on community building. From a design perspective, Oksanen and Stahle (2013) developed 
a framework of spaces that facilitate the establishment of connections. They introduce "collaboration and communication enabling spaces" as a design characteristic which enables the formation of networks and social capital. When spaces have shared physical spaces and spatial arrangements that promote interaction this will support people's motivation, ability, and opportunity to share knowledge and experiences. Heerwagen et al. (2004) link the physical environment to collaboration, and concluded that spatial layouts offering better accessibility, visibility and short walking distances affect face-to-face interaction. Additionally, when coworking spaces offer workers the possibility to participate in community events, interaction is further encouraged with the purpose of entering communities and creating new contacts (Björklund et al, 2011).

Capdevila (2014) compares coworking spaces with local micro clusters. Clusters are characterized by local circulation of information and knowledge that are shared by all co-located actors and can lead to differentiation and competitiveness of workers. As a result of diversity and complementarity of the members, fruitful interaction is stimulated between members which in turn can lead to synergetic collaborations.

Several studies hint that for interaction to be effective and fruitful, merely co-locating people is not sufficient. Boschma (2005) and Torre \& Rallet (2005) discern various types of proximity. Geographical proximity facilitates or strengthens relationships (Boschma, 2005). However, being physically together does not automatically imply that professionals will start sharing information and is therefore not sufficient. Cognitive proximity also plays a role in having effective interaction. In order to successfully communicate, process and learn from each other the cognitive bases between actors should be close to each other (Boschma \& Lambooy, 1999). This means that people with similar knowledge or expertise may learn from each other in an efficient way and at the same time they can extend their cognitive scopes (Nooteboom, 2000). Besides geographical and cognitive proximity Boschma discusses organizational proximity (coordination of knowledge), social proximity (socially embedded relations on micro-level) and institutional proximity (rules and regulation). In order to reach the desired interaction effects, such as knowledge exchange in coworking spaces, different types of proximity should be complemented and coincided (Boschma, 2005).

\subsection{Coworking spaces: A space for innovation}

In this paper, one of the questions is whether coworking spaces enable innovation. There is no template for achieving innovation, which makes it a hard concept to grasp (Greengard, 2009). Jamrog et al. (2006) define innovation as "how organizations create value by developing new 
knowledge or by using existing knowledge in new ways". Nordfors (2009) mentions that fundamentally, innovation means that something new is introduced. Den Hertog and De Jong (2007) define innovation as a new idea or concept of how to organize a solution to a problem. As a result of global competition, labour mobility and dispersed knowledge across organizations, the innovation landscape has changed. Increasingly, innovation emerges at the crossroads of knowledge domains (Leonard-Barton, 1995; Carlile, 2004). Companies realize that they cannot rely solely on innovation capability from within, which is why external actors have become an increasingly crucial part of companies' innovation capability (Freeman, 1991). Chesbrough (2003) coined a term for this innovation approach: open innovation.

Open innovation is facilitated in coworking spaces through their physical and social environment. Senoo et al. (2007) recognized the physical environment as a significant factor for knowledge creation and learning. As far as the design of the environment, coworking spaces are mostly creatively designed spaces. Symbolic creative environments are needed for creative work as creativity is considered a critical aspect of innovation (Csikszentmihalyi, 1996). However, besides facilitating the creative process, the spatial environment also influences accessing the right people to obtain critical information, which often can be found within knowledge locations (Allen, 1977). Penn \& Hillier (1992) suggest that spatial layout plays a key role in facilitating the effective use of human resources in innovation-based locations. Their research showed that in laboratory environments spatial patterns affect movement patterns and that it plays a role in making people passing each other's workstations resulting in knowledge exchange.

With regards to the social environment Botsman and Rogers (2011) note that social interaction contributes to innovation. Hence, it is important that managers of coworking spaces support formation and nurturing of social capital (Olma, 2012; Amin \& Roberts, 2008). Social interaction increases the chance of knowledge exchange between different people at coworking spaces. However, the success of this social interaction would depend on the type of contacts or, what Granovetter (1973) calls, networks and strength of ties available in a specific coworking space. These ties range from weak ties to strong ties (depending on the closeness and interaction frequency). Weak ties can be particularly useful for information retrieval and can help to diffuse innovations (Granovetter, 1983). Strong ties on the other hand, are important because they are more accessible and willing to help (Krackhardt, 1992). Groot (2013) showed that coworking spaces foster both weak and strong ties. In these spaces weak ties provide workers with information and assist in finding business opportunities, while strong ties provide support and access to resources. Coworking spaces foster network formation and it can be seen as an innovation marketplace. The social, collaborative 
environment of coworking spaces provides (in) direct access to supplementary resources and capabilities necessary for successful innovation (Das \& Teng, 2000) because of the facilitated proximity of workers from different companies. However, to our knowledge, no studies have systematically investigated to what extent innovation is enabled in coworking spaces.

\section{$\underline{2.3 \text { Coworking strategies for interaction }}$}

To support interaction and innovation, an array of strategies can be deployed by coworking spaces. The management of coworking spaces might promote interaction. By coordinating and connecting its members or tenants it can build bridges to connect distant worlds- industries beyond your own- to generate new products or services. Hargadon (2003) calls these people "connectors". The connecting role of management can lead to a reduction of time needed to find appropriate connections and to an increase in the chance of the connections being valuable (Hering \& Philips, 2005). This role of management also helps to build the reputation of the coworking space. This effect fits with Chemannur \& Paeglis (2005), who found that perceived quality of management is closely related to firm reputation. Management can also play a key role in connecting internal users to key players outside the coworking space. These roles are referred to as boundary spanning roles (Daft, 2006). Purposes of boundary spanners is to detect relevant information about changes in the external environment, and to represent the interests of a company to that environment. Boundary spanners are important because they represent the interests of members to the external environment, so they will feel their interests are being represented. In turn, results of these boundary spanning activities will lead to higher levels of legitimacy amongst members, municipalities, and client groups (Jemison, 1984).

Interaction can also be impacted by carefully managing the mix of workers. Handpicking tenants or members helps to increase the chance that they interact, work together and benefit from each other's presence (van Winden et al., 2012). Based on this notion, some founders of coworking spaces seek specialization (Link \&Scott, 2006). Specialization helps to gain a reputation as "the place to" be within a certain industry and it can be a way to lure companies away from other coworking spaces. There is some evidence that specialized knowledge locations grow faster than those with a heterogeneous member mix (Link \&Scott, 2006).

Social networking tools such as social events, awareness creating activities, and social network sites also encourage interaction. Under the assumption that there is a positive relationship between networking and business performance (e.g. Brüderl \& Preisendörfer, 1998) an increasing number of network activities are organized in coworking spaces. Deskmag.com (2015) held a global 
coworking survey and reports that the majority of coworking spaces hold two events each month and around $15 \%$ host 10 or more events per month. Many of these activities have as an aim to create awareness amongst members of coworking spaces. Dourish \& Belotti (1992) discuss that being aware of other coworking member's supports synergistic group behavior. This links with theory regarding collaborative working, which highlights that information and knowledge sharing of group and individual activity, are central for successful collaboration (e.g. Galegher \& Kraut, 1990). Social networking sites contribute to the creation of awareness amongst coworking space members. It enables members to present themselves, connect to a local network, and develop and maintain relationships with other members (e.g. Ellison et al., 2007).

\subsection{Conceptual framework}

Thus far we have discussed how coworking spaces can be conceived as locations that foster interaction and innovation. We also discussed tools which can be employed to promote interaction. This leads to a proposed framework of analysis based on insights from literature (Figure 1). For this study we identify four strategies which can be applied to foster interaction. 1) "Coworking space manager as connector", 2) "Regulating the mix of workers", 3) "Interior design for interaction", and 4) "Tools for networking"

As far as interaction this can be between members within the coworking space, and between coworkers and parties outside the coworking space. For the purpose of this study we are interested in both forms of interaction and we are particularly interested in collaborative interaction. This is a form of interaction in which people discuss issues that are related to their work, learning or solving problems in a collaborative way (Moller, 1998).

The proposed strategies may lead to various forms of interaction and entrepreneurial outcomes. Porter (1994) hints that clustering facilitates access to new customers and suppliers (Porter, 1994). It may also lead to other benefits such as cooperative working (e.g. Leforestier, 2009, Spinuzzi, 2012), gaining access to new knowledge (van Winden et al., 2012), and new business opportunities (Groot, 2013). In this paper, we are specifically interested in whether coworking spaces enable innovation. Here we will look at innovation as when "new projects" arise (Jamrog et al., 2006; Nordfors, 2009), as well as new ways to acquire "New clients", "New suppliers" or "New knowledge and ideas" as a consequence of coworking. In the following empirical section the effectiveness of the projected strategies for interaction and innovation will be analyzed. 


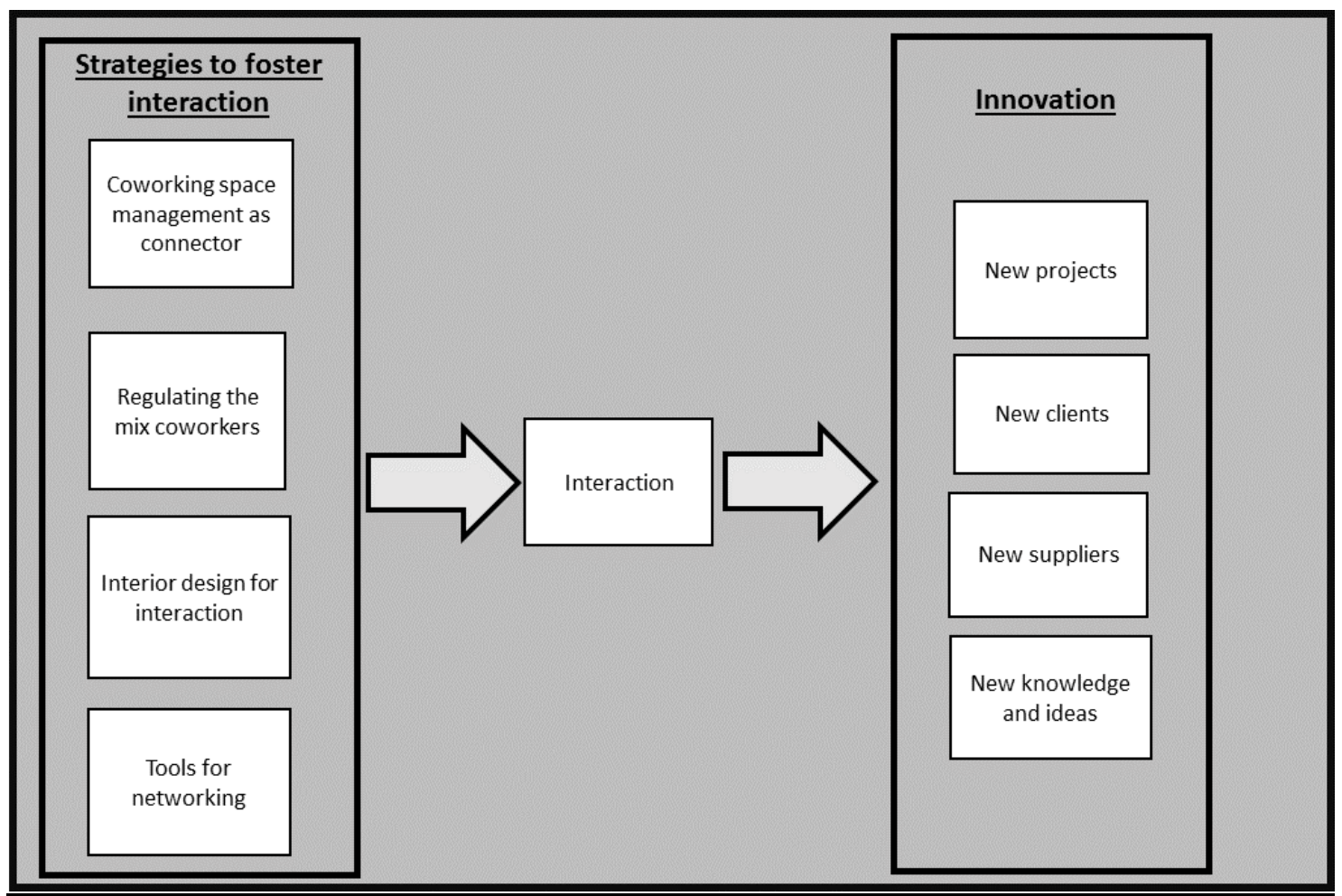

Figure 1: Potential tools to foster interaction and innovation

\section{$\underline{\text { 3. Methods }}$}

This research has a qualitative and exploratory nature because there is limited information on the subject of coworking strategies for interaction and innovation. The goal of this research is to learn about how employed strategies by coworking spaces affect the process of interaction and innovation. For this purpose a case study approach was chosen. A case study is defined as 'a strategy for doing research which involves an empirical investigation of a particular contemporary phenomenon within its real life context using multiple sources of evidence' (Robson, 2002). Despite the fact that statistical generalization is a limitation, it can serve as a precursor for rigorous empirical testing in future research (Merriam, 1998). In order to provide more generalizable foundation for this exploratory research, multiple cases were used (Yin, 2003). The evidence from multiple cases is often considered more compelling, and the overall study will therefore be more robust (Herriot \& Firestone, 1983).

\section{$\underline{3.1 \text { City selection }}$}

One can witness a global spread of the coworking phenomenon with a concentration in "creative cities" (Florida, 2004), such as San Francisco, New York, London, Berlin, and Amsterdam 
(Moriset, 2013). This study focused on Amsterdam as an area of research, which was reported as one of the European cities where coworking is widely popular (Deskmag.com, n.d.).

Reasons for the growth of coworking in Amsterdam are various. Firstly, there is a growing group of self-employed workers (Hatfield, 2015). This can be explained by patterns of globalization, technological change, and the effects of the 'great recession', which led to the elimination of the need for certain jobs and the private sector has struggled to create new ones (Hatfield, 2015). These developments brought unemployment, which in turn has led to many workers becoming selfemployed. Given that self-employed workers have flexibility in choosing a work location, a considerable group opts for working in coworking spaces. Secondly, in Amsterdam many office spaces are unutilized (Parool, 2015). Reasons often stated for this are decreased demand for office space as consequence of the economic crisis, companies moving to more attractive buildings or locations, and companies having more flexible work staff leaving underutilized workspace. To monetize on these empty spaces, some of them are rented as coworking spaces. Thirdly, Amsterdam is an attractive city for many foreigners who migrate as a result of the crisis and look for better work opportunities. Professionals who temporarily move to Amsterdam can benefit from coworking to get in touch with locals, both on a social and a professional level. Fourthly, ever since the 1990s the Dutch government has developed measures to help increasing labor market flexibility. These measures led to increasing flexibility of working hours and work location flexibility. Gradually, flexible workers became an accepted phenomenon in the Netherlands (Teulings and Hartog, 1998) and as a result many workers work (full- or part-time) from coworking spaces. These above mentioned factors make Amsterdam a particularly relevant case area for this research.

\section{$\underline{3.2}$ Case selection}

As preliminary investigative research 5 coworking places were visited in order to have a good understanding on which types of coworking spaces exist and how they differ from each other. We selected the cases based on the criterion that they should have an explicit strategy and organizational platform to entice "cross-pollination" amongst members.

The cases which were visited but excluded from this research are: Spaces, WeWork and Seats2Meet. Spaces and WeWork are large multinationals and after having spoken with multiple members of both spaces it seemed that interaction with other companies is not per sé the main reason for working there. Despite the efforts of both coworking spaces to have entrepreneurs and companies interact, several members mentioned to be there mainly for office flexibility purposes. However, both multinationals give room to many activities which could be defined as coworking. At 
Seats2Meet most workers do not pay rent but are merely required to log in via a social network and mention what they are working on. After several visits and talks with users, the assumption was made that many workers with workplace flexibility are there to get work done, focusing on productivity and less on collaborating. As a result, the cases which were selected for this research are: A-Lab and FreedomLab.

\section{$\underline{3.3 \text { Sites and Sample }}$}

Before collecting data, each of two coworking spaces were visited and interviews were held with the director (A-Lab) and community manager (FreedomLab). In these interviews the vision, strategies and aims of the coworking space were discussed. After the interviews, permission was asked to spend time in each of the spaces to observe the locational environment and address various members and discuss their experiences with the spaces. Several days were spent at the 3 locations not only to get a good idea of the dynamics in coworking spaces but also to 'feel' what is going on (Gill \& Johnson, 2002). Spending time there gave a good understanding of the coworking environment and coworking strategies. The interviews, direct observation and talks with members enabled us to construct an overview of interaction strategies which are synthesized in Table 1.

Table 1: Interaction Strategies in Coworking Spaces

\begin{tabular}{lll}
\hline & FreedomLab & A-Lab \\
\hline Management as connector & - Active board recruiting outside CWS contacts & - Active board managing outside CWS contacts \\
& - Active board integrated among members and linking members & - Active board linking members \\
Regulating the mix of workers & - Onboarding procedure with a focus on open attitude & - Creating clusters of tentants of \\
& - Mananging disciplines of tenants (complementary) & creative and technology industries \\
& - Group of researchers to complement entrepreneurism & - Entry and exit policy \\
Design for interaction & - One printer \& coffee machine & - Coffee house \\
& - Homely themed rooms & - Themed laboratories to link \\
& - One entrance & creatives with technology \\
& - Open and secluded spaces & - Hallways to foster encounters \\
& - Walls for work display & - Brainstorm areas \\
& & - Website with live feeds \\
& - Collective lunch & - Company names and locations visible \\
& - Social media sites & - Sport and Social events \\
& - Meditation \& Yoga & - Presentations \\
& - Workshops & - Website connecting workers \\
& & within and outside CWS
\end{tabular}

The sample consisted of 18 respondents. At FreedomLab 8 people were interviewed (8\% of the members) and at A-Lab 10 people were interviewed (13\% of the members). See Table 2 for the characteristics. 16 respondents defined themselves as founder or director of their company and only 
2 were employed. To collect a broad range of perspectives of the coworking concept and maximize the diversity of the sample, members were interviewed from various industries, and with a diversity of coworking experience (from 2 months to 4 years).

\begin{tabular}{rrr}
\hline \multicolumn{2}{c}{ Table 2: Characteristics of Samples Across Two Coworking Spaces } & A-Lab \\
\hline Coworking Space & FreedomLab & \\
Respondents & & 10 \\
Avg. age & 39 & 43 \\
Membership type of space: & & \\
- Desk in open space & 3 & 0 \\
- Seperated Office & 5 & 10 \\
& & \\
Industry: & & $\mathrm{n} / \mathrm{a}$ \\
- Strategic Consultancy & 3 & $\mathrm{n} / \mathrm{a}$ \\
- Data Consultancy & 1 & 3 \\
- Software Development & 1 & $\mathrm{n} / \mathrm{a}$ \\
- Copywriting & 1 & 1 \\
- Community Services & $\mathrm{n} / \mathrm{a}$ & 2 \\
- Architecture & $\mathrm{n} / \mathrm{a}$ & 1 \\
- Online & $\mathrm{n} / \mathrm{a}$ & $\mathrm{n} / \mathrm{a}$ \\
- Animator & 1 & $\mathrm{n} / \mathrm{a}$ \\
- Research & 1 & 1 \\
- Photography & $\mathrm{n} / \mathrm{a}$ & \\
- Journalism & $\mathrm{n} / \mathrm{a}$ & \\
\hline Note: "n/a" indicates that data are not available & &
\end{tabular}

\section{$\underline{\text { 3.4 Data collection }}$}

The aim of the study was to analyze how coworking spaces affect the innovation process of their members. Because of the exploratory nature of this research the employed technique for collecting data were semi-structured interviews. Interviews with members lasted between approximately 13 and 32 minutes. An interview protocol served as a guide for the interviews. It contained questions about a typical day of a member at the coworking space, motivations to work there, how the physical space is used, examples of interaction, and questions on outcomes of such interaction. At the start of the interview the respondent was asked whether the preferred language was English or Dutch. Therefore, the interview protocol was designed in English and also translated into Dutch. It was translated by one of the authors who is a native speaker, and to ensure accuracy (Brice and Richardson, 2009) it was afterwards translated back to English by two Dutch speakers who speak fluent English. Before collecting the data, the interview protocol was tested on 2 people across the 2 coworking spaces. 


\section{Data Analysis: Preliminary results}

The collected data was analyzed to find out how different coworking strategies lead to interaction and how they facilitate entrepreneurial outcomes. For the purpose of this paper, the authors have adopted a descriptive narrative with salient quotes, rather than empirical style to summarize the most important findings which emerged from this study. The findings were interpreted per coworking space to have a better understanding of the importance of the different employed strategies for the members of the coworking spaces. Each case will start with a short description of the coworking space, followed by an analysis of the employed strategies and will end with entrepreneurial outcomes for the members. Figure 4 depicts a schematic illustration of the key findings and forces which affect interaction and innovation.

\section{$\underline{4.1 \text { FreedomLab }}$}

The FreedomLab Campus was inaugurated in 2013 and is located in Eastern Amsterdam and currently has 100 members. It is designed as a big comfortable house, while dressed with all kind of appliances to experience the 21st century challenges (e.g. drones, Google Glasses, graphic tablets, 3D printers). In addition to its conventional role of utility, the campus has the role of an unconventional learning environment supporting didactics such as unforeseen learning, creative learning, serendipity, inefficient learning (FreedomLab.org). FreedomLab offers two membership options: Guesthouse and Freezone memberships. Guesthouse memberships are meant for innovation and creative managers who seek a hang-out to continuously be inspired by latest trends and technologies. They get access to all facilities but rent separated office spaces. Freezone seats on the other hand are spaces which can be rented in large shared spaces. The seats and services are meant for creative professionals with some experience in the field of engineering, design and/or education.

FreedomLab hosts conferences and organizes workshops for its members. There is also a strong link to research. There is an independent research lab and a European think tank which have as an aim to encourage creative thinking on the future of our society. The inspiration for future challenges stems from the knowledge of a group of nearly 300 experts, visionaries and scientists, with whom FreedomLab has collaborated in recent years in the areas of innovation, change, future and technology. FreedomLab also has a college called the "FreedomLab Crossover Innovation College" where workshops are offered to externally recruited clients regarding the topic of social innovation and responding to social change. 


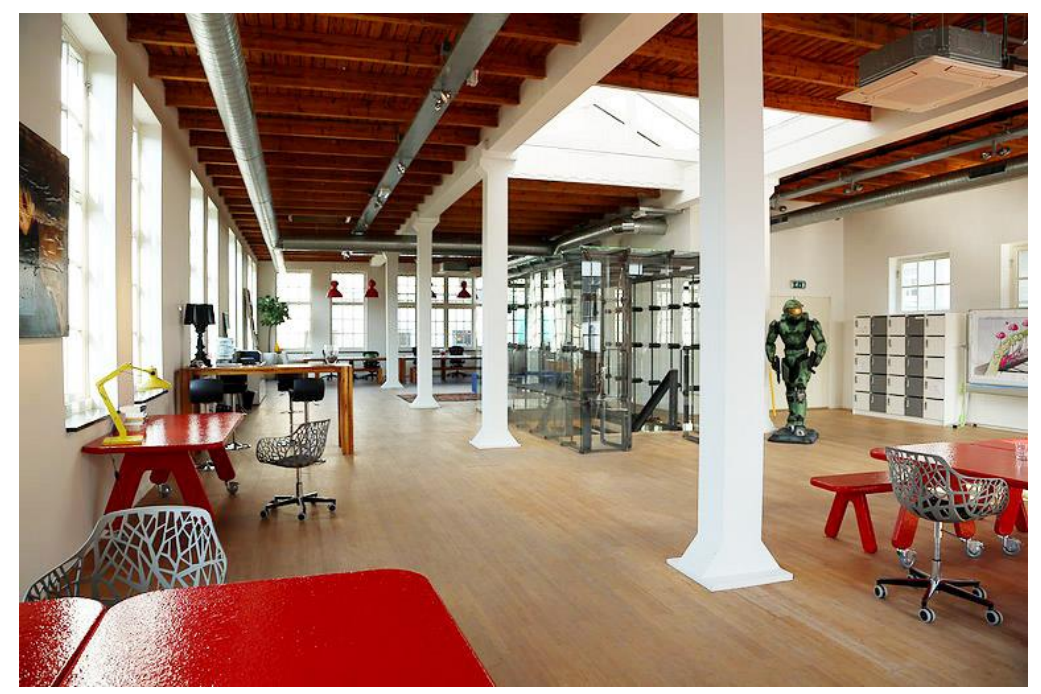

Figure 1: Shared office spaces at FreedomLab (Source: FreedomLab.org)

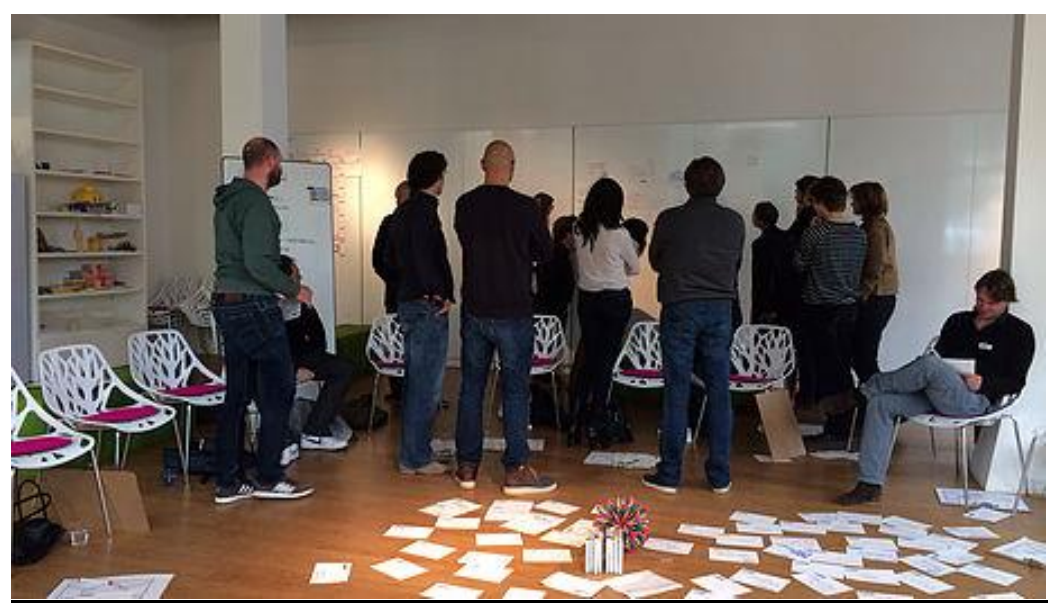

Figure 2: Example of a space for workshops and the innovation college (Source: FreedomLab.org)

\subsection{Strategies for Interaction}

The following part discusses the results of interviews held with 8 members of FreedomLab (see table 2 for the characteristics). The results are organized per strategy and the most significant quotes will be revealed to illustrate the effectiveness of the concurring strategy.

Management as connector: Interaction between members mostly occurs in order to have access or combine various types of knowledge and resources. The community manager plays an important role in identifying these, both internally and externally. To become fully integrated and aware of the community, the manager focusses on visibility and integration by sitting on different 
spots every day. The manager also lunches with the members every day and interacts with them. The bridging function works because the manager is an integral part of the community, and aware of the skills, activities, developments and problems of the members. Thus, the manager can see and exploit opportunities for members to connect and to be of value for each other's business.

"The role of the community manager is crucial for the members. She is really among us and constantly sends the signal "talk to each other, talk to everyone." Copywriter

FreedomLab functions as a consultancy firm and recruits external clients for its innovation college. In this college workshops are offered to clients who deal with the topic of innovation and change. When the clients are recruited, management offers a customized toolbox and connects the client to internal members for the delivery of the service. Therefore, apart from connecting internal members the management of FreedomLab plays a bridging role in connecting members to external companies. This extends the scope of business opportunities for various members.

"At FreedomLab we set up a design thinking method to help children think about world problems. FreedomLab recruited a health care institution and after being introduced to each other we are now looking into applying our method to their patients." Managing Director

Connecting various internal members intensifies network creation and stimulates the creation of weak ties. The intensive process, in which members cooperatively perform tasks for a client, induces close interaction between members and intensifies interaction. This creates insight in what the skills and capabilities are of the various members. As a result, the flow of information from member to member is facilitated by the creation of these networks.

"I was asked to deliver the imaging for a corporate client of FreedomLab and worked closely with other local members. This led to deeper connections which go beyond the simple lunch talks. You really get insight in what other people are doing around here!" Creative Director 1

An additional role of the manager is by being a "promotor" for network events. Many events are organized and an important role is to create awareness amongst members of the value of such events. The value can be regarding the content of the events and regarding the opportunities for networking. During events members often expose what they are working on and as a consequence people easily connect to other workers. Therefore, the community manager stimulates people to go to networking events and stresses the availability of knowledge in the form of a large pool of potential relevant contacts. 
Regulating the mix of workers: At FreedomLab there is no specialization policy regarding the professional background of members. However, there is an onboarding procedure; members are selected based on having open attitudes, entrepreneurial drive and shared interests with regards to innovation and social issues. This results in a diverse mix of industries in which members are active and a broad scope of professional skills and backgrounds. Yet, there is still an attempt to have complementary disciplines rather than overlapping. Nevertheless, the cognitive bases of the members are fairly proximate leading to a common spoken language as a result of shared interests and attitudes. According to the respondents, the common denominators are curiosity, openness, extrovertedness and accessibility. The respondents share that all members have an interest for the future and are focused on innovation, which makes establishing contacts an easy process. People step up to each other often and are eager to talk about work and learn from each other.

"At FreedomLab there is a variety of people with mixed backgrounds. But everybody who walks around here is really good in his or her field .This is really inspirational!" Creative Director 2

Interestingly, the value of having a variety in expertise is highly appreciated. The proximate cognitive bases facilitate effective interaction amongst members, yet, the learning process is strengthened as a result of diversity. Respondents mention that the fact that not everybody is dealing with the same topics is inspirational and entices interaction. A respondent even emphasized that having people around who are very close to one's own business is less interesting. These are the people one has the least contact with. He expressed that working around people from the same industry is too traditional.

"It really becomes interesting to find out if a specific technology works in a completely different industry. I spoke with people here who are active in education and now we are discussing how we can apply virtual reality in the educational context." Creative Director 1

Interior design for interaction: At FreedomLab there are open shared spaces and separated office spaces. The different types of spatial lay-out lead to different types of interaction. Open shared spaces are communication enabling and secluded offices to a lesser extent. The location of one's desk plays an important role in the facilitation of inter-member interaction. Respondents who have desks at open spaces mentioned that because people pass by their desks frequently, interaction occurs regularly and easily which does not occur with members who rent separate office spaces.

The creative design of the entire space works inspiring and the different themes in the various room works multi-functional. The small cozy rooms are good for one-on-one talks and the 
larger spaces are good for brainstorming and conceptualizing. Respondents also mentioned that workers who have desks in open shared spaces and are regularly present have much interaction with other members because they see each other often and get to know each other quicker. On the contrary, members who are in separated offices or spend less time at the coworking space have less interaction with other members of the coworking space.

"The biggest part of the week we are working at the clients so when we are finally in our office we really need and want to update each other and know what has happened. We spend most of the time together in our office." Strategic Consultant

Clever design of the entrance to the building, with one door and one corridor stimulates the convergence and intersection of members. Moreover, facilities such as the coffee machine and printer are also managed smartly. Both are placed at the entrance and are shared by all members. As a result these facilities create good places for short talks. Respondents mention that many members often have quick talks there but that it remains fairly superficial. These design characteristics entice interaction and play a supporting role in the members getting to know each other.

Having display opportunities leads to exposure of work. Many members use the walls of the large spaces to discuss, brainstorm and hang up what they are working on. One of the companies that is specialized in visualizing uses the big walls to hang up posters and projects they are working on. Respondents expressed that many people who pass by look at the work and comment on it and therefore interaction can be promoted.

"I saw a poster hanging from $X$ and saw that the phrases used in it were not catchy nor captivating. I addressed it and helped them to improve it. In my field of work I know how to capture the attention of an audience. I didn't charge them anything for it!" Copywriter

Tools for networking: FreedomLab has various tools to entice networking. These can be divided into formal networking events, such as academy presentations and workshops, and informal network events, such as collectively organized lunches, improvisation classes and meditation sessions. Most respondents mentioned that the free lunch policy and community events play a big role in supporting networking behavior. The lunches at FreedomLab are free for its members. These are served at fixed times resulting in collective moments where most members coincide. The large tables enable members to sit next to each other and interact. Respondents mentioned that this is crucial to (in)formally meet other members. Additionally, during the lunches members or external parties get a stage to present what they are working on. These are moments which lead to exposure 
of the undertaken activities, knowledge about available skills and capabilities, and it entices people to interact and react to performed business activities.

"During lunch I met a strategist who helps start-ups in setting up their business. He really gave me some insightful tips on how to run my business." Copywriter

Many respondents expressed that whenever works allows them to, they try to attend various formal and informal sessions. It are moments where members can get valuable information and access important knowledge but it are also moments when members get to know each other in an (in)formal way. The frequency of having and attending these events influences the level of interaction between members. One member emphasizes that by attending various events insight is created in the potential role of other members.

"Attending various activities is really important because you really get to know who is around here. I attended an improvisation course which was really fun. I got to know people I've met in other events even better! The more of these touch-points, the better you get to know people!" Creative Director 1

There are various digital networking tools used at FreedomLab (a Facebook, Facebook, Slack, and WhatsApp) to promote interaction. Respondents expressed that the employed digital social networking tools can work informative but entice interaction to a lesser extent. People share information which goes beyond what is happening within FreedomLab and despite the fact that some respondents see the added value of it, most categorized it as entertainment. Respondents expressed that the positive side of these digital social network tools are that they project an overview of the members within the campus. However, mostly it functions as a post factum tool and not an interaction tool.

\subsection{Entrepreneurial outcomes}

None of the respondents in the sample started new projects with other members as a result of working at FreedomLab. However, many workers mentioned to have open attitudes to embark on new entrepreneurial ventures but, to date none had experienced concrete opportunities. Interestingly, by working at FreedomLab many members expressed to have access to new clients and suppliers. When FreedomLab recruits clients for its innovation college many internal members are hired for delivery of the service. For the selected members this means access to new clients. Some members mentioned that when onboarding the campus, this is promised to them and for some this is one of the reasons to stay at FreedomLab. Additionally, as a consequence of having members working together intensively for recruited clients, the value of the individual members is exposed 
and the relevance for each member's work can become apparent. This has led to many workers being introduced to new potential suppliers.

"I used company X to visualize my mission and vision after having worked with them for one of the clients recruited by FreedomLab" Creative Director2.

The narratives of the respondents support the idea that social capital is positively affected by having various networking events. This can be attributed to the relatively small size of the network and the large number of commonly organized activities. Because of the variety of events and organized moments, the value of members is exposed leading to valuable insights and ideas. Moreover, it increases the awareness of local skills and expertise. Respondents expressed that this can reduce search time when looking for potential suppliers or additional knowledge.

Respondents mentioned that the fact that there is no specialization in regulating the mix of workers has positive effects with regards to getting new knowledge or ideas. Some respondents mentioned that by interacting with others from different professional backgrounds they had valuable tips regarding conducting business. The fact that there is a diversity of specialisms and shared interests and attitudes make workers approachable and accessible for specific knowledge and solutions. Moreover, by having many social networking moments this process is facilitated. Respondents expressed that they would normally have to pay for input but at FreedomLab there seem to be low barriers for sharing information or knowledge.

With regards to the interior design of FreedomLab, the possibility to display work has impact on interaction and knowledge exchange. Displaying work on big walls has led to members commenting on it which in turn leads to new ideas. Additionally, its playful, homely and creative design has impact when clients are invited to the site. They are usually positively impressed and this can facilitate (sales) meetings.

\section{$\underline{5.1 \mathrm{~A}-\mathrm{Lab}}$}

A-Lab was established in 2013 and is housed in the former Shell Lab at the banks of the IJ in the northern part of Amsterdam. It currently hosts 80 members. A-Lab is a coworking space where start-ups and professionals meet, where crossovers occur within the new media and technology, and where businesses can be established and expanded. They offer 5000sqm where users can rent separated desks, offices or inspiration spaces and by means of various themed laboratories (e.g. journalism, culture, music) they connect the various occupants. The separated offices are delivered empty and the members have complete freedom in designing the space. Coffee house "The Coffee 
Virus" is housed in the ground floor in the lobby and serves as an in-house canteen and as a space for events. In recent years, the neighborhood where A-Lab is situated has been vacated by large industry and is now in full transformation towards being one of the prime locations of Amsterdam. The area has become a creative hub for artists, cooperatives, and youth brands such as MTV, IDTV and Red Bull. The management body of A-Lab is fully aware of the rapid urban development around it and is in close contact with the municipality, surrounding businesses and neighbor university regarding cooperative initiatives.

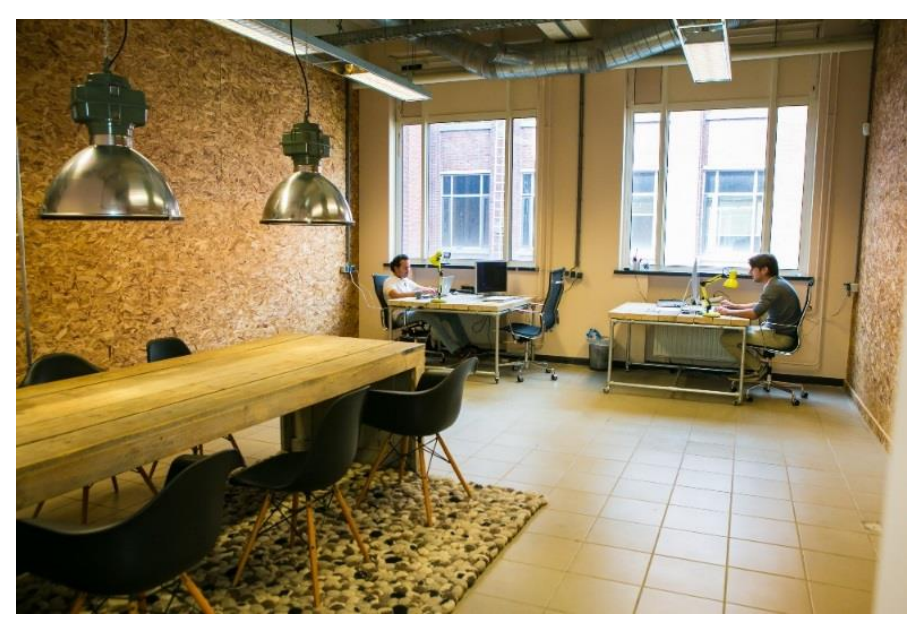

Figure 3: Example of an office space at A-Lab.

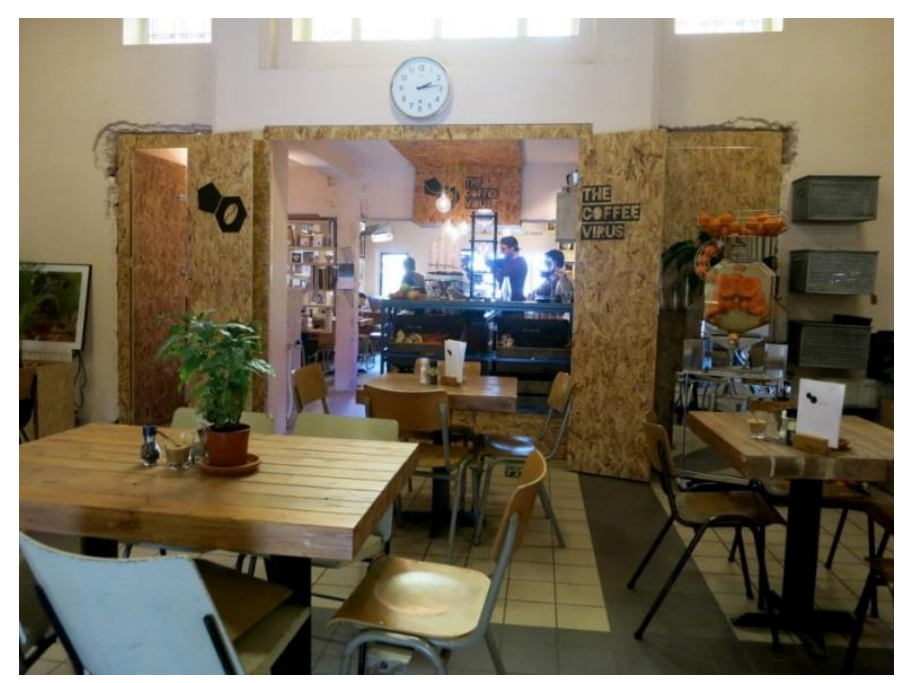

Figure 4: Coffee House "The Coffee Virus" at the entrance of A-Lab. 


\section{$\underline{5.2 \text { Strategies for interaction }}$}

The following part discusses the results of interviews held with 10 members of A-Lab (see table 2 for the characteristics). The results are organized per strategy and the most significant quotes will be revealed to illustrate the effectiveness of the concurring strategy.

Management as connector: The management of A-Lab sits in a separate office and is not amid members. Even though this does not promote integration with the community, the open-door policy results in members walking easily in and out of the office and addressing management with issues, questions or requests. The manager also walks around the building and talks to the members. He is actively showing engagement, participation, and interest in the members and their activities. Having awareness of the business activities is crucial and is highly valued by members who often depend on others for their business. Members often seek short-term solutions to problems or opportunities or have long-term strategic decisions to make. By being aware of the needs of the different members, the manager can quickly connect members to relevant others. Moreover, he even crosses the physical boundaries of A-Lab by connecting external parties to internal members. A-Lab is constantly trying to arrange meetings with external parties with high strategic value, by tracking developments and opportunities in the external environment, leading to long-term opportunities for the members. This leads to the extension of network of knowledge domains and as a consequence may lead to new business opportunities. Members expressed that this role of management is highly valued.

"We develop applications and for one of our clients we needed an animator. We addressed our community manager and he introduced us to one of the other members here who are specialized in this. Another project which we are working on is an app which connects geolocations to the open data of the Amsterdam city archive. This originated here and was facilitated by A-Lab who connected us to an internal member with links to the municipality." App developer

"One of the strong points of A-Lab is that management here thinks on a high strategic level. For instance, they connected us to a group of Hungarian journalists with connections to the BBC. As a result we are now meeting regularly to think about the topic of Journalism and Innovation. They also invited a fund which stimulates journalism and now we meet them regularly. The management here is really important for meeting others. They really think about what is best for us." Lournalist 1

Regulating the mix of workers: There is a diverse mix of users at A-Lab. The policy of A-lab is to have a focus on the creative and technology industries. Yet, this still results in a vast diversity in 
professional background, specialisms and interests. Various respondents expressed that it is a positive aspect of A-lab to have members with complementary skills and backgrounds. Despite of the professional diversity, the cognitive bases are close which can be a good foundation for interaction. Especially, the fact that members are geographically close is perceived as useful and facilitates interaction. From the practical point of view, problems or opportunities can be dealt with in short terms. The following quote illustrates the practicality and value of diverse backgrounds in the coworking space:

“Sometimes I need a photographer or a music producer. It's really great that I don't have to search a lot for them. They are all here inside this building." Owner multi-media agency.

Despite the fact that diversity is valued, it appears that in early phases of start-ups having workers from the same industry can be beneficial for learning purposes. One respondent expressed that it can be particularly valuable for brainstorming.

"Sometimes we really do miss experienced people in our field. We are a relatively young company and we miss people discuss issues which are related to our industry." Architect1

In addition, the narratives revealed that there is a large mix of members in terms of "business phase". There are many start-ups and there are various companies in more mature phases. Start-ups can benefit from brainstorming with each other because they deal with generic start-up issues. Examples which were given were e.g. how to effectively set up accounting systems or whether extra people should be hired. This learning process is facilitated by spatial proximity, visibility and awareness of the other members. At the same time, the learning process is stimulated by having more experienced businesses within a coworking space. Larger companies can be seen as educational bodies in generic business consultation.

Design for interaction: The building is designed with circular hallways with entrances to separate offices. These are rented entirely or shared. There are no large shared open spaces. Various respondents expressed that as a result of the spatial layout and design of the building there is a lack of visibility and accessibility. As a consequence it does not favor face-to-face interaction. Respondents expressed that companies who rent an entire office tend to remain inside their offices whereas smaller companies who share offices interact more and also leave offices more regularly to seek interaction in the hallways. One respondent from a more developed company expressed that interaction is not always desired. Companies often just need an office with all the basic requirements where work can get done. Interaction with others is a secondary function and can be sought if needed. 
"We shouldn't forget that we are all here to work. If we want interaction we can look for it. The main purpose is to have a space where I and my people can work." Director Web studio

One of the design characteristics which was expressed to strongly contribute to making personal connections is the coffee house. Besides functioning as a place for consumption, it also facilitates meetings, lunches and social events. It has a role of a central hub enabling the formation of networks. The shared physical space has an informal atmosphere which supports people's motivations and opportunity to share knowledge and experiences. Most respondents expressed that the coffee house is a locus for (business) lunches and an important central place where much interaction takes place and new projects can start. Several respondents mentioned that because workers interact there in an informal manner this often leads to exchange or valuable knowledge can lead to new opportunities. One example was the following:

"The coffee house is a place where we sit very often to chat and joke about new fun projects which would connect us all here within A-Lab. It was there where we invented the "Coffeecopter". A drone which brings coffee to the members. It started as a fun idea but it became an A-Lab project which involved 4 members. Next month the BBC is coming to use it for a new program they're starting."

\section{Creative Director3}

Tools for networking: A-Lab organizes various events where workers can meet and interact. Most respondents mentioned the monthly drinks and the "lunch roulette". Both are organized on a monthly basis. The monthly drinks are organized in the coffee house and are meant for all members. During this event members can interact informally and have face-to-face contact with other members. Respondents expressed that most members who come to the drinks are open to conversations and therefore interaction with new members takes place regularly. Several members expressed that this event strongly enhances the coworking community. At the "lunch roulette" free lunches are offered to members who apply for it. Members who apply for the lunch roulette are coupled to (ir)relevant others and have one-on-one lunches. These couples can be made at random or are pre-defined by the management of A-Lab. This can be based on business compatibility or complementarity. An example of such a match is the following between an owner of a multi-media agency and a director of a web studio:

"I work with young adults who are trying to get back into the labor market. At a lunch roulette I was connected at random to an owner of a web studio. He also happens to teach at elementary schools about web maintenance. My clients expressed that they would also like to learn about web maintenance. Now I'm trying to get some funding so that I can hire him." Owner multi-media agency. 
"The lunch roulette is very good to make useful contacts. I was matched with an owner of a multimedia agency who is now going to make a video for one of my new products which I will have to pitch soon at a fair." Director Web studio

Even though attendance at these events show patterns of irregularity, respondents expressed that during these events serendipitous contacts often lead to fruitful discussions or meetings. In addition, the events create awareness of what various companies are doing within A-Lab. As a result, when people know what others are doing in their direct surrounding, interaction and potential collaborations are facilitated. Moreover, the strength of ties between different members is enforced during events.

\section{$\underline{5.3 \text { Entrepreneurial outcomes }}$}

The interviews revealed various outcomes. There was one example of a new project. This originated in the coffee house of A-Lab during a Friday afternoon drink. The central location of the coffee house where multiple events are organized played an important role. During events at the coffee house different companies within the A-Lab network are connected, which otherwise might have stayed unconnected. Workers meet each other there and interaction and knowledge exchange is strongly stimulated by its informal setting. This setting may open doors to new ideas. When new ideas occur inside A-Lab and workers express that additional skills and knowledge is needed, the role of the management becomes important in making the right in- or external connections. They have an overview of the internal members and a lot of relevant strategic external contacts. Having an internal diverse mix of members with a broad range of expertise facilitates this process. Concurrently, the process in which management connects various companies leads to many new clients or suppliers for the distinct members.

"When we invented and developed the Coffeecopter we used Bright TV/RTL Z to make a video and shoot an item about it. They are one of the members here in this building. A-Lab helped us in making this connection. This went very easy. Now our film already went viral!" Creative Director3

Several respondents mentioned that having a large range of companies around which can provide complementary skills and capabilities and who are easily accessible can lead to useful suppliers. Often these suppliers show high willingness to help or service other members. Most of the times for competitive prices and sometimes even without monetary compensation. 
"Having all these different people around here makes work really easier. Whenever I need a photographer or an editor I can find one here. And even better, we can have things done cheaper here."

\section{Owner multi-media agency.}

A recurring point is that it is beneficial in conducting business to be aware of the internal users and what they are capable of. Awareness can be created and is enforced by attending multiple networking events. As a result the value of the members gets exposed which can foster the creation of networks and forges a broader base of potential bridges to available clients, suppliers or knowledge. The design of the premises can also facilitate awareness. Creating visible and accessible spaces fosters interaction and knowledge spill-overs. For instance, having work displayed in hallways facilitates the awareness of what different members are active with. As a consequence members address other workers and react to their work. In turn, these interactions can lead to new knowledge or ideas for both parties.

Interestingly, respondents expressed that the availability of human resources is an important outcome of being in A-Lab. One respondent even expressed that the company had moved to A-Lab to specifically look for qualified staff. He expressed that the turn-over of people and companies is high in a coworking space and that this increases the chances of finding good staff. One member indicated that as a consequence of a bankruptcy of a start-ups this led to the hiring of new people.

"It is really important to find good people. A place like this makes it easier because a lot of people walk in and out. When one of the start-ups here went bankrupt we hired one of the programmers" Creative

\section{Director4}

One member emphasized the importance of the internal social network page when it comes to accessibility of human resources. This platform is used by internal members to share that they are searching for additional staff or interns. Other benefits of the social network site lays in providing opportunities for internal and external exposure of the members and their activities. Extra benefits besides providing the occasional interesting posts, were not expressed. 


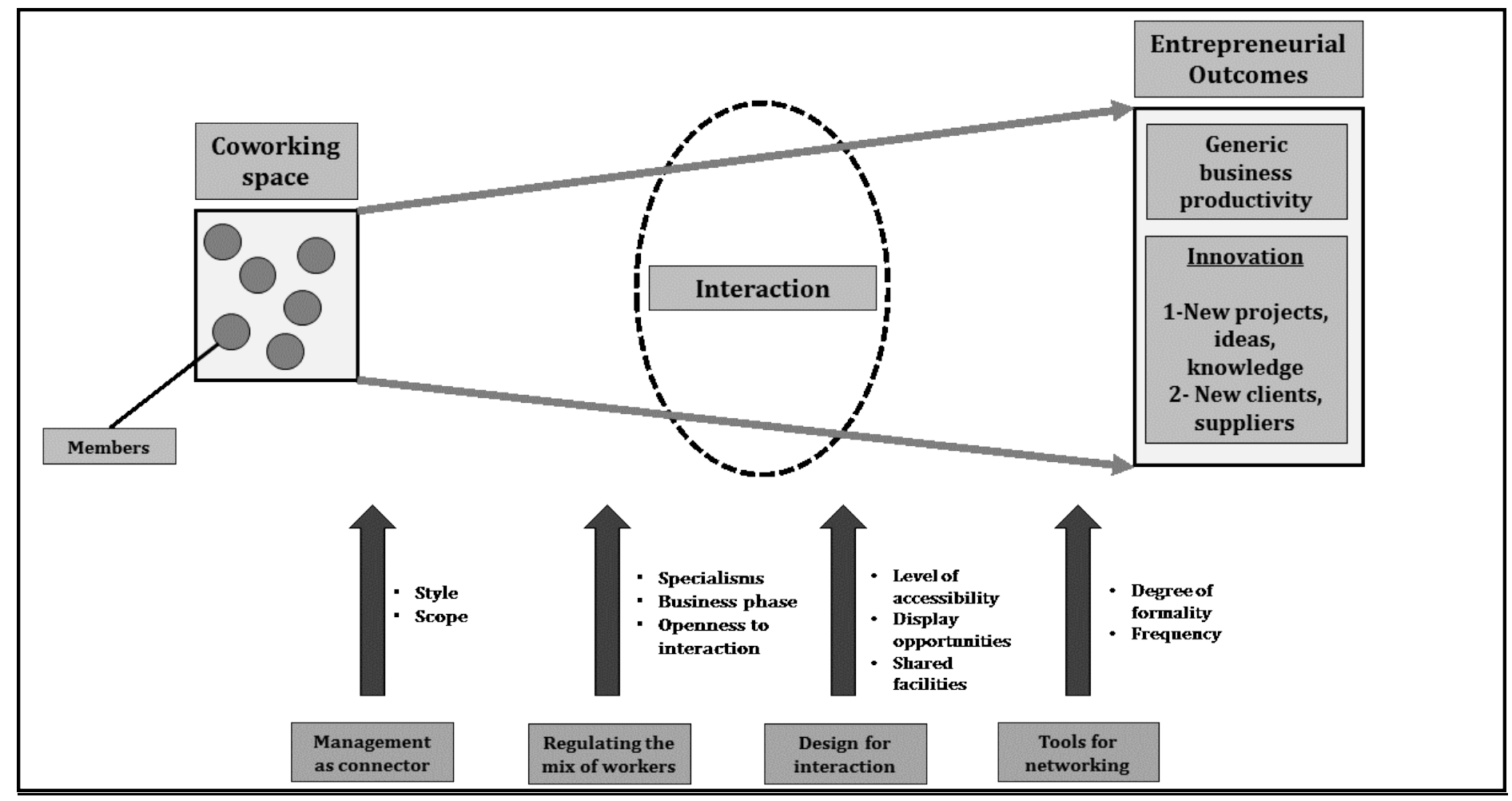

Figure 4: Schematic illustration of key findings: forces affecting interaction and entrepreneurial outcomes.

\section{$\underline{6 \text { Conclusion }}$}

This paper described and analyzed four strategies which coworking spaces can employ to entice interaction and foster innovation: coworking space management as connector, regulating the mix of workers, interior design for interaction and tools for networking. Two coworking spaces in Amsterdam were analyzed on how these strategies are applied and it was explored how they can benefit their workers. Earlier work states that many workers go to coworking spaces to join a community or to access a network which can be important for their business. Yet, both literature and our evidence suggests that co-locating people does not automatically lead to interaction nor to innovation. Co-locating people in a coworking space can help but applying the right strategic tools can enhance the effect.

We developed a framework which linked four strategic management tools to interaction and innovation. At the widest level of generality, we have seen that interactions between members can be built on the strategic effort made by the coworking space. We have seen that many connections between members are constructed around the need for capabilities and technologies of other members. The role of a coworking space can be to facilitate the transfer of value from those who have 
the capabilities and technologies to those who seek to use them. In highly complex coworking networks, a successful coworking space is one which has a very clear idea of its mix of members, and how it is broken down to basic, distinctive, internal and external needs and how these relate to the requirements of others. We emphasize that for coworking space managers the ability to strategically manage the space and assemble a package of basic product and services and tailor that package to the requirements of the workers is a key element of its competitive strategy. To support this, there are a number of issues regarding the proposed strategies which we shall revisit here and emphasize their importance.

The role of management is important for detecting in- and external opportunities for its members. In line with earlier research, many members depend on others for new business opportunities and the connecting role of management facilitates this process. However, members have different needs requiring different types of connections. These needs can vary between shortterm solutions or opportunities, such as needing a supplier or seeing a potential sales opportunity, and long-term opportunities, such as the need for help in strategic growth decisions. Thus, a coworking space manager should have a clear and broad scope of in- and external networks and have the ability to accommodate the distinct needs of different members, both on the practical and strategic level.

In managing the mix of members it became clear that achieving the right mix in a space is a challenging task. Nevertheless, a main finding is that diversity plays a role in enticing interaction. Diversity can be in professional background and expertise. Members with different backgrounds and expertise can be valuable to each other by offering opportunities to apply technologies or new knowledge in different or unfamiliar contexts. Yet, having people around with comparable levels of expertise can also be valuable for exchanging experiences and related knowledge. Diversity also relates to the phase of companies. Small start-up companies can learn from the experience and knowledge from larger and more experienced companies. Concurrently, large companies can benefit from unsuccessful start-ups in the sense that they can provide human resources. In determining the mix of workers or companies it is also paramount to understand the reasons for workers to choose a coworking space. Assessing the motivation can reveal whether members just need a location to work, a test environment for ideas, or a location to grow as a start-up. Different intentions lead to different levels of interaction. To assure a good mix of members, managers may apply entry- and exit policies related to different forms of diversity. Assessing intentions of members, attitudes, interests, skills and capabilities are examples of characteristics which can be taken into consideration. 
As far as promoting interaction, the design of a coworking space plays an important supportive role. In line with earlier research, having common physical areas were perceived to entice interaction. Interaction is enforced when knowledge is made visible and accessible by having work of members exhibited or displayed. When coworking spaces are designed with separate rooms, interaction is not promoted and depends more on the attitude and willingness of the members. Herein the role of management as connector comes in by stimulating that members attend networking events. The attractiveness of the spaces (features ranging from playful aesthetical design, themed rooms, relax areas, art display) as well as having a central shared meeting hub is an important characteristic. However, attractiveness or aesthetics are hard to define or measure, but the value for internal users and external visitors was recognized and supported in many ways (Oksanen \& Stahle, 2013).

Having sufficient tools for networking helps to "push" members to connect with each other. The design of the space has a supportive role and, especially, the role of a central shared location has a significant effect on interaction. We must reiterate the importance of having a series of networking activities since it increases awareness of other workers' activities and capabilities which in turn supports interaction. However, we stress that coworking spaces should take a portfolio approach of networking activities including both formal and informal networking events. Informal events stimulate workers to get to know each other better and enforce inter-member relationships and formal events induce professional awareness and value.

The most significant entrepreneurial outcomes which were revealed are access to new clients, new suppliers, and access to new knowledge and ideas. A new category which was revealed is that coworking spaces provide valuable access to human resources. From the perspective of innovation it became clear that the social context of coworking spaces supports knowledge exchange but that it is a long-term process which requires multiple "touch-points" amongst members. Combining the right interaction strategies with a sufficient number of networking tools can facilitate the process of innovation. Further research is needed to test this process and to find out how coworking spaces can facilitate more joint projects between members. Yet, for the practicing manager of coworking spaces, it is also important to emphasize that many workers also view coworking spaces as one of many locations which can be chosen for generic business productivity.

In light of the limited nature of literature which address strategies to differentiate between successful and unsuccessful interactions, this research has attempted to make a first step in clarifying this. Managerially, this research offers insight in how coworking space managers can manage their spaces to reap the benefits of success. Theoretically, a specification of the linkages between 
interaction strategies and innovation can provide a useful framework for future research. The empirical part narrated here provides a first attempt to better understand coworking strategies and how they contribute to the success of workers.

In view of the fact that this is a working paper, the certainty and generalizability of the conclusions are limited by the data set and the number of analyzed coworking spaces. With a larger data set and more cases, the relationships uncovered here could lead to a more complete exploration between employed coworking strategies and innovation.

\section{$\underline{\text { References }}$}

Amin, A., \& Roberts, J. (2008). Knowing in action: Beyond communities of practice. Research policy, 37(2), 353-369.

Appelbaum, E. (2013). The impact of new forms of work organization on workers. Work and Employment in the High Performance Workplace, 120-146

Björklund, T., Clavert, M., Kirjavainen, S., Laakso, M., \& Luukkonen, S. (2011). Aalto University Design Factory in the eyes of its community.

Boschma, R. (2005). Proximity and innovation: a critical assessment. Regional studies, 39(1), 61-74.

Boschma, R. A., \& Lambooy, J. G. (1999). Evolutionary economics and economic geography. Journal of evolutionary economics, 9(4), 411-429.

Botsman, R., \& Rogers, R. (2011). What's mine is yours: how collaborative consumption is changing the way we live. London: Collins.

Brice, W. D., Richardson, J. (2009). Culture in family business: a two-country empirical investigation. European Business Review 21.3 (2009), 246-262

Brüderl, J., \& Preisendörfer, P. (1998). Network support and the success of newly founded business. Small business economics, 10(3), 213-225.

Carlile, P. R. (2004). Transferring, translating, and transforming: An integrative framework for managing knowledge across boundaries. Organization science,15(5), 555-568.

Chemmanur, T. J., \& Paeglis, I. (2005). Management quality, certification, and initial public offerings. Journal of Financial Economics, 76(2), 331-368.

Chesbrough, H. (2003) The Era of Open Innovation, MIT Sloan Management Review, Spring 2003, Vol. 44 No. 3, 34-42

Capdevila, I. (2014). Different Inter-Organizational Collaboration Approaches in Coworking Spaces in Barcelona. Available at SSRN 2502816.

Coworking in Amsterdam. (n.d.). Retrieved March 02, 2016, from

http://www.deskmag.com/en/coworking-spaces-in-amsterdam-netherlands-483 
CoworkingWiki (n.d.). Retrieved March 02, 2016, from

http://wiki.coworking.org/w/page/16583831/FrontPage

Csikszentmihalyi, M. (1996). Flow and the psychology of discovery and invention. New Yprk: Harper Collins.

Das, T. K., \& Teng, B. S. (2000). A resource-based theory of strategic alliances. Journal of management, 26(1), 31-61.

Daft, R. (2006). Organization theory and design. Cengage learning.

Den Hertog, P., de Jong, G. (2007) Randstad's business model of innovation: Results from an exploratory study in the temporary staffing industry. Innovation: management, policy and practice (2007) 9, 351-364

Dourish, P., \& Bellotti, V. (1992). Awareness and coordination in shared workspaces. In Proceedings of the 1992 ACM conference on Computer-supported cooperative work (pp. 107-114). ACM.

Ellison, N. B., Steinfield, C., \& Lampe, C. (2007). The benefits of Facebook "friends:" Social capital and college students' use of online social network sites. Journal of Computer-Mediated Communication, 12(4), 1143-1168.

Freeman, C. (1991). Networks of innovators: a synthesis of research issues.Research policy, 20(5), 499-514.

Gandini, A. (2015). The rise of coworking spaces: A literature review*.Ephemera, 15(1), 193.

Galegher, J., \& Kraut, R. E. (1990). Technology for intellectual teamwork: Perspectives on research and design. Intellectual teamwork: Social and technological foundations of cooperative work, 1-20.

Gill, J., \& Johnson, P. (2010). Research methods for managers. Sage.

Granovetter, M. S. (1973). The strength of weak ties. American journal of sociology, 1360-1380.

Greengard, S. (2009) Finding the essence of innovation, CIO Insight, 01 June 2009, vol./is. /105, 3840

Groot, J. (2013). Coworking and Networking: How sharing space contributes the to competitveness of independent professionals. Unpublished Master's Thesis. University of Amsterdam, the Netherlands.

Hargadon, A. (2003). How breakthroughs happen: The surprising truth about how companies innovate. Harvard Business Press.

Harrigan, K. R. (1988). Strategic alliances and partner asymmetries. Graduate School of Business, Columbia University.

Hatfield, I. (2015). Self-employment in Europe. London: Institute for Public Policy Research.

Heerwagen, J. H., Kampschroer, K., Powell, K. M., \& Loftness, V. (2004). Collaborative knowledge work environments. Building research \& information,32(6), 510-528.

Hering, D., \& Philips, J. (2005). Innovation Roles, The People You Need for Successful Innovation (White Paper). Herndon, VA: NetCentrics Corporation. 
Herriott, R. E., \& Firestone, W. A. (1983). Multisite qualitative policy research: Optimizing description and generalizability. Educational researcher, 14-19.

Hillman, A. (2008). 6 reasons to start coworking. Retrieved March 2 from http://mashable.com/2008/11/07/reasons-to-start-coworking/\#0RcXbSvNdEqQ.

Hutchins, E. (1991). Organizing work by adaptation. Organization Science,2(1), 14-39.

Jamrog, J., Vickers, M., Bear, D. (2006) Building and sustaining a culture that supports innovation. Human Resource Planning 29 3, 9-19.

Jemison, D. B. (1984). The importance of boundary spanning roles in strategic decision-making. Journal of Management Studies, 21(2), 131-152.

Kloosterman, R.C. (2008). Walls and bridges: knowledge spillover between 'superdutch' architectural firms. Journal of Economic Geography, 8(4), 1-19.

Krackhardt, D. (1992). The strength of strong ties: The importance of philos in organizations. Networks and organizations: Structure, form, and action, 216, 239.

Lave, J., \& Wenger, E. (1991). Situated learning: Legitimate peripheral participation. Cambridge university press.

Leforestier, A. (2009). The co-working space concept. CINE Term Project. Indian Institute of Management (IIMAHD), Ahmedabad.

Leonard-Barton, D. (1995). Wellsprings of knowledge: Building and sustaining the sources of innovation. University of Illinois at Urbana-Champaign's Academy for Entrepreneurial Leadership Historical Research Reference in Entrepreneurship.

Link, A. N., \& Scott, J. T. (2006). US university research parks. Journal of Productivity Analysis, 25(12), 43-55.

Matlay, H. (2008). The impact of entrepreneurship education on entrepreneurial outcomes. Journal of Small Business and Enterprise Development, 15(2), 382-396.

Merriam, S. B. (1998). Qualitative Research and Case Study Applications in Education. Revised and Expanded from" Case Study Research in Education.". Jossey-Bass Publishers, 350 Sansome St, San Francisco, CA 94104.

Moriset, B. (2013). Building new places of the creative economy. The rise of coworking spaces.

Moller, L. (1998). Designing communities of learners for asynchronous distance education. Educational technology research and development, 46(4), 115-122.

Nonaka, I., \& Takeuchi, H. (1995). The knowledge-creating company: How Japanese companies create the dynamics of innovation. Oxford university press.

Nooteboom, B. (2000). Learning and innovation in organizations and economies. OUP Oxford.

Nordfors, D. (2009). Innovation Journalism, Attention Work and the Innovation Economy. A Review of the Innovation Journalism Initiative 2003-2009.Innovation Journalism, 6(1), 1-46. 
Oksanen, K., \& Ståhle, P. (2013). Physical environment as a source for innovation: investigating the attributes of innovative space. Journal of knowledge management, 17(6), 815-827.

Oldenburg, R. (1989). The great good place: Café, coffee shops, community centers, beauty parlors, general stores, bars, hangouts, and how they get you through the day. Paragon House Publishers.

Olma, S. (2012). The Serendipity Machine. A Distruptive Business Model for Society, 3.

Penn, A., \& Hillier, B. (1992). The social potential of buildings: spatial structure and the innovative millieu in scientific research laboratories.

Porter, M. E. (1998). Cluster and the new economics of competition.

Powell, W. W. (1987). Hybrid organizational arrangements: new form or transitional development?. California management review, 30(1), 67-87.

Renzulli, L. A., Aldrich, H., \& Moody, J. (2000). Family matters: Gender, networks, and entrepreneurial outcomes. Social forces, 79(2), 523-546.

Robson, C. (2002). Real world research: A resource for social scientists and practitionerresearchers (Vol. 2). Oxford: Blackwell.

Senoo, D., Magnier-Watanabe, R., \& Salmador, M. P. (2007). Workplace reformation, active ba and knowledge creation: From a conceptual to a practical framework. European Journal of Innovation Management, 10(3), 296-315.

Spinuzzi, C. (2012). Working alone together coworking as emergent collaborative activity. Journal of Business and Technical Communication,26(4), 399-441.

Teulings, C., \& Hartog, J. (1998). Corporatism or competition?: labour contracts, institutions and wage structures in international comparison. Cambridge University Press.

Torre, A., \& Rallet, A. (2005). Proximity and localization. Regional studies,39(1), 47-59.

Turnbull, P., Ford, D., \& Cunningham, M. (1996). Interaction, relationships and networks in business markets: an evolving perspective. Journal of Business \& Industrial Marketing, 11(3/4), 44-62.

Van Winden, W. , De Carvalho, L., Van Tuijl, E. , Van Haaren, J. , \& Van den Berg, L. (2012). Creating Knowledge Locations in Cities. Innovation and integration challenges.

Yin, R. K. (2003). Case studies research: design and methods. Thousand Oaks, Sage.

Zonneveld, J. (2015, February 15). In Amsterdam krijgen kantoren vaker een tweede leven Amsterdam - PAROOL. Retrieved March 02, 2016, from http://www.parool.nl/parool/nl/4/AMSTERDAM/article/detail/3851858/2015/02/15/InAmsterdam-krijgen-kantoren-vaker-een-tweede-leven.dhtml 